\section{Oesophageal plastic repair for symptomatic ballooning following circular oesophageal myotomy and correction of oesophageal atresia}

\author{
Michael Zer, Enrique Freud, \\ Sylvia Grozovski
}

\begin{abstract}
Two patients with refractory anastomotic stenosis and symptomatic ballooning of the upper oesophageal pouch following repair of long gap oesophageal atresia are described. In both cases a circular myotomy had been used to elongate the proximal oesophageal segment at the time of primary repair. Both patients were successfully treated by Y-V plasty of the oesophageal stenosis and tailoring of the dilated segment.

(Thorax 1997;52:487-488)
\end{abstract}

Keywords: oesophagoplasty, oesophageal ballooning, circular oesophagomyotomy.

Circular oesophagomyotomy was first introduced in 1969 to elongate the proximal oesophageal pouch at the time of primary repair of long gap oesophageal atresia. ${ }^{12}$ It has been claimed that up to three circular myotomies can be performed over the proximal pouch without irregularity of the oesophageal contour on the oesophagogram and without causing functional delay. "Smooth bulging" without formation of diverticulae and without causing dysphagia or stenosis has been reported on barium swallowing following this myotomy procedure. ${ }^{4}$ Symptomatic ballooning and pseudodiverticulisation of the denuded oesophageal mucosa are, however, well described. ${ }^{5-7}$ In most instances these findings are not associated with significant clinical problems but cases have been described where severe progressive dysphagia has required major surgical intervention and repair with either colonic interposition ${ }^{7}$ or local resection and reanastomosis. ${ }^{8}$

\section{Case reports}

CASE 1

A 31 week baby girl weighing $1250 \mathrm{~g}$ was born with VATER complex, including oesophageal atresia with a distal T-E fistula. A primary anastomosis was performed using Livaditis' circular myotomy. No postoperative complications appeared but the recovery was very slow with severe swallowing difficulties. Oesophagography performed on the $23 \mathrm{rd}$ day re- vealed a hypotonic upper pouch with good passage of contrast material. No stricture or delay was seen. Feeding difficulties continued, however, and on the 62nd day a mild anastomotic stricture was found which was successfully dilated by a $12 \mathrm{~mm}$ balloon, but there was no long term improvement. During the next month the upper pouch progressively dilated and the stricture recurred despite several additional dilatations.

At the age of 3.5 months a second operation was performed. The anastomosis was dilated, a Y-V oesophagoplasty was performed with tailoring of the upper pouch, and a feeding gastrostomy was introduced. After surgery swallowing significantly improved. At the age of 10 months she could eat semisolid food well, but a mild stricture was again found and was once more dilated. The gastrostomy was closed at the age of one year. At present, at the age of four years, she has no feeding problems.

CASE 2

A 35 week old baby boy weighing $1700 \mathrm{~g}$ underwent surgery soon after delivery for oesophageal atresia with a distal T-E fistula. At surgery long gap atresia was found and primary repair with end-to-end anastomosis became possible after Livaditis' circular myotomy. The postoperative course was uneventful. No stricture of the anastomosis was found, but the patient could swallow only liquid food and showed failure to thrive.

Repeat oesophagograms at the age of eight months demonstrated significant ballooning of the upper oesophagus with severe dysmotility and a relative anastomotic stricture (fig 1A). Dilatations of the stricture were performed surprisingly easily but were not effective since no real fibrotic stricture was present. At the age of 10 months the infant underwent further surgery. Tailoring of the upper dilated pouch and $\mathrm{Y}-\mathrm{V}$ oesophagoplasty of the narrow part (fig 1B) were performed without undue difficulty. The postoperative course was again uneventful. Oesophagography performed on the ninth day after surgery showed a clear improvement of the oesophageal contour and barium passage (fig 1C). An improvement in feeding was evident immediately, as well as a growth spurt. Eighteen months after the operation the patient has no swallowing difficulties.

\section{Discussion}

The technique of circular oesophageal myotomy may allow elongation of the proximal oesophageal pouch by up to $2-3 \mathrm{~cm}$ and thereby permit the surgeon to perform a primary anastomosis in many cases of moderately long gap oesophageal atresia. The blood supply to the segment of denuded mucosa and to the more distal portion of the proximal oesophageal pouch is not impaired. ${ }^{124}$ The mucosa at the site of the myotomy is, however, easily distensible and therefore even a slight anastomotic stenosis will lead to some degree of dilatation. Abnormal motility and the negative pressure zone in the mediastinum may contribute to progression of the mucosal dilatation leading eventually to ballooning or pseudodiverticulisation. For- 

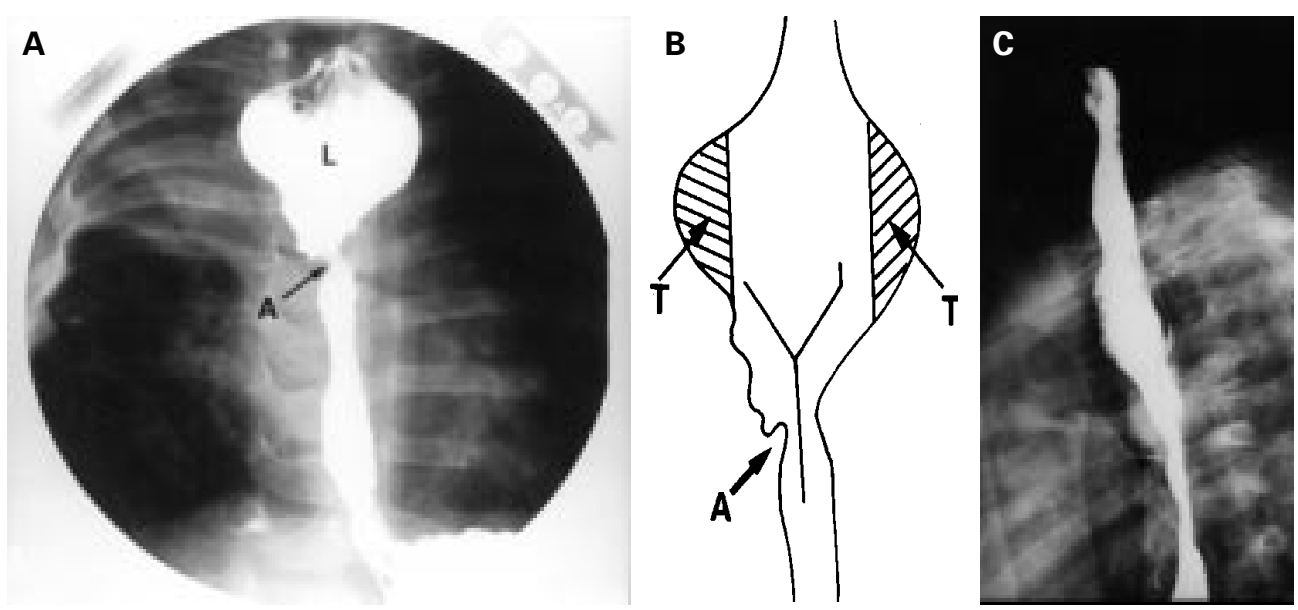

Figure 1 (A) Oesophagogram in case 2 at the age of eight months. $A=$ anastomotic stenosis; L=Livaditis' area of ballooning. (B) Diagram showing the Y-V plasty at the anastomotic $(A)$ stricture and tailoring $(T)$ areas. (C) Oesophagogram after oesophagoplasty.

tunately, most of these cases can be adequately managed conservatively but symptomatic patients may require surgical intervention. This can be a challenging exercise and the use of a gastric or intestinal conduit involves a major surgical procedure. Local plastic repair of the anastomotic stenosis with tailoring of the dilated proximal oesophageal segment may offer a less radical solution to this problem and has the specific advantage of preserving oesophageal function.

1 Livaditis A, Björck G, Känström LE. Esophageal myotomy. Scand $\mathcal{F}$ Thorac Cardiovasc Surg 1969;3:181-5.
2 Okmian L, Livaditis A. Esophageal atresia: successful primary anastomosis after operative elongation of the upper pouch $Z$ Kinderchir 1969;7:2-6

3 de Lorimier AA, Harrison NR. Long gap esophageal atresia. f Thorac Cardiovasc Surg 1980;79:138-41.

4 Vizas D, Ein SH, Simpson JS. The value of circular myotomy for esophageal atresia. F Pediatr Surg 1978;13:357-9.

5 Siegel NJ, Shackelford GD, McAlister WH, Bell NJ. Circular esophageal myotomy simulating pulmonary or mediastinal pseudocyst. Radiology 1980;136:365-8.

6 Scheeberger AL, Scott RB, Rubin SZ, Machida H. Esophageal function following Livaditis repair of long gap esophageal atresia. F Pediatr Surg 1987;22:779-83.

7 Otte JB, Gianello P, Wese FX, Claus D, Verellen G, Moulin D. Diverticulum formation after circular myotomy for esophageal atresia. F Pediatr Surg 1984;19:68-71.

8 Ein SH, Shandling B, Heiss K. Pure esophageal atresia: outlook in the 1990s. F Pediatr Surg 1993;28:1147-50.

Thorax 1997;52:488-489

\section{An unusual case of flail chest: surgical repair using Marlex mesh}

\author{
A G Heriot, F C Wells
}

\footnotetext{
Department of Cardiothoracic Surgery, Papworth Hospital, Papworth Everard, Cambridge, UK

A G Heriot

F C Wells

Correspondence to: Mr A Heriot, 47 Upper Tooting Park, London SW17 7SN, UK.

Received 17 January 1996 Returned to authors 4 April 1996

Revised version received

17 June 1996

Accepted for publication

27 June 1996
}

\begin{abstract}
The case history is presented of a patient with neurofibromatosis with a chest wall defect present from birth. Abnormal rib development had resulted in a flail segment with painful paradoxical movement and unsightly costal cartilage protrusion. Chest wall reconstruction using Marlex mesh resulted in an excellent cosmetic and functional repair.

(Thorax 1997;52:488-489)
\end{abstract}

Keywords: neurofibromatosis, flail chest, Marlex mesh.

Chest wall deformities associated with neurofibromatosis may be a consequence of spinal deformities ${ }^{1}$ or may result from the presence and treatment of chest wall tumours. Primary chest wall deformities are very rare but may benefit from the use of surgical techniques developed for the treatment of malignancies.

\section{Case report}

A 32 year old woman with neurofibromatosis presented with a large left upper anterolateral chest wall defect. On clinical and simple radiological assessment the second, third and fourth ribs had failed to develop with the costal cartilages resulting in a flail segment and profound anterior protrusion of the second to fifth costal cartilages adjacent to the sternum (fig 1). Symptomatically this caused intermittent pain but also psychological distress due to the cosmetic appearance which may have been associated with a past history of anorexia nervosa. A computed tomographic scan of her thorax demonstrated the deformity but provided limited additional information regarding the soft tissues present at the site. Surgery was performed under general anaesthesia to correct this defect (fig 2).

A left submammary incision extended into the axilla was used to conceal the scar. The left pectoralis major muscle was mobilised and reflected cranially along with the overlying breast and skin. This allowed direct visualisation of the left lateral sternal edge, the ribs, and the intercostal muscles. The costal cartilages of the second to fifth ribs inclusive 
Figure 1 Postero-anterior chest radiograph showing failure of development of the left anterior third to fifth ribs.

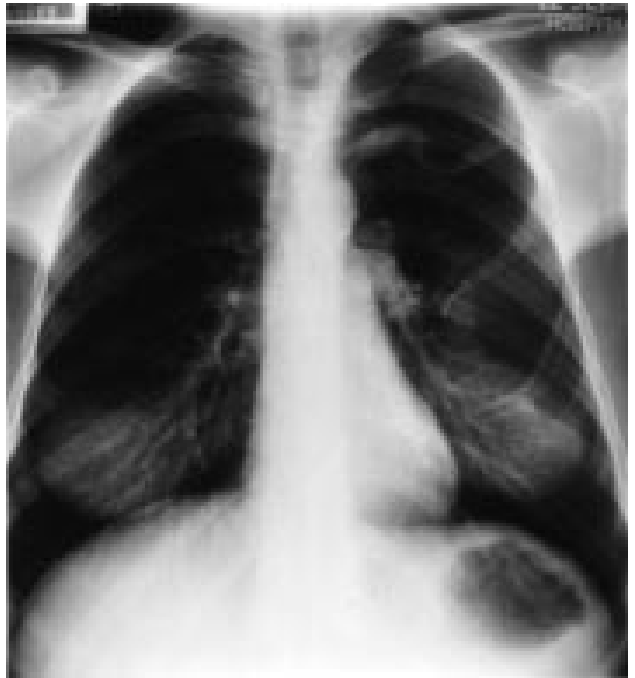

Figure 2 Computed tomographic scan demonstrating left anterior chest wall deformity with overdevelopment and gross anterior protrusion of the costal cartilages.

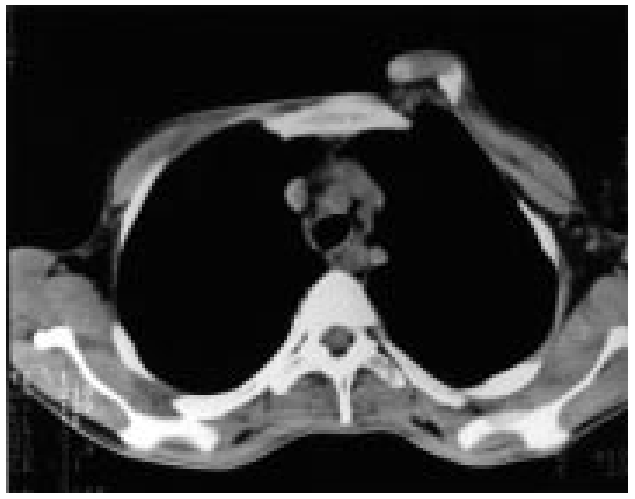

were enlarged and protruded anteriorly from the lateral edge of the sternum. The second and fifth ribs remained attached to their corresponding costal cartilages but the anterior ends of the third and fourth ribs were attached by fibrocartilaginous bands which had no inherent strength. The bodies of the third to fifth ribs tapered to fine flexible fibrocartilaginous strands which provided no support for the chest wall, resulting in a flail segment. The intercostal muscles between the ribs appeared normally developed although the intercostal spaces were considerably widened. After identifying the components of the chest wall that were present, the costal cartilages protruding anteriorly from the sternum were excised. There was a residual degree of anterior angulation of the lateral side of the sternum which was impossible to correct as a result of the pull of the normal ribs and their attachments on the right side. The fifth rib was detached from its costal cartilage and repositioned more superiorly. The flail segment was reconstructed by using a double thickness Marlex mesh. This was placed over the flail segment and sutured to the second and sixth ribs and the pleural cavity was closed. The floating incompletely developed third and fourth ribs were then fixed to the overlying mesh by encircling stitches. Haemostasis was secured, a chest drain and Redivac drain were positioned, the pectoralis major was returned to its normal position covering the mesh and a layered closure was performed.

The patient was pleased with the cosmetic result and there was no symptomatic or clinical evidence of any paradoxical chest wall movement. She was discharged six days after surgery.

\section{Discussion}

Chest wall reconstruction is most commonly required following resection of chest wall neoplasms and may occasionally be necessary in patients with neurofibromatosis following development of a malignant schwannoma. ${ }^{1}$ Primary spinal deformities in patients with neurofibromatosis resulting in thoracic deformity have been reported ${ }^{2}$ but primary congenital chest wall deformity is very rare. In the case described the deformity was independent of any form of neoplasm and had distressed the patient from both the cosmetic appearance and the pain resulting from paradoxical chest wall movement. The cosmetic deformity resulted predominantly from the overgrowth of the costal cartilages and could be corrected by simple excision. As no soft tissue resection was required, primary closure of the incision resulted in an excellent cosmetic appearance, eliminating the necessity of tissue transfer and flap mobilisation which is commonly required following resection to fill the resulting tissue defect. ${ }^{3}$

The flail segment posed a different challenge as any reconstructive procedure must restore the functional integrity of the thoracic cage, thereby eliminating any independent movement. ${ }^{4}$ This frequently results in the use of prosthetic materials such as methyl methacrylate which provide an appropriate degree of rigidity to the reconstruction. Graham first described the use of Marlex mesh ${ }^{5}$ and it is frequently used. It may be sutured under tension in a single plane to provide support or, by combining it with methyl methacrylate sandwiched between two layers of mesh, the prosthesis may be moulded to fit the contours of the lateral chest wall. ${ }^{6}$ Adequate tension was generated by directly suturing the mesh to the ribs. Attachment of the floating ribs to this prosthetic extension of the thoracic cage effectively generated a united thoracic unit.

The application of techniques which have been developed predominantly for repair of chest wall defects following resection of neoplasms allowed a cosmetic and functional repair of this rare defect with a high degree of patient satisfaction.

1 Campo-Paysaa A, Stagnara P, Fauchet R, Biot B, Nouvel A Neurofibromatose mesenterique. A propos d'une observation. Chirurg Pediatr 1982;23:411-3.

2 McKenna RJ, Mountain CF, McMurtrey MJ, Larson D, Stiles QR. Current techniques for chest wall reconstruction: expanded possibilities for treatment. Ann Thorac Surg 1988 ; 46:508-12.

3 Mathes SJ. Chest wall reconstruction. Clin Plastic Surg 1995; 22:187-98.

4 Stephens DR, Grotting JC. Soft tissue reconstruction. Coverage of the chest wall and spine. Orthoped Clin North Am erage of the chest

5 Graham J, Usher FC, Perry JL, Barkley HT. Marlex mesh as a prosthesis in the repair of thoracic wall defects. Ann Surg 1960;151:469-79.

6 Eschapasse H, Gaillard J, Fournial G, Berthoumieu F, Henry $\mathrm{E}$, Hornur E, et al. Utilisation de prostheses en resine pour la reparation des vastes pertes de substance de la paro thoracique. Acta Chir Belg 1977;76:281-5. 